4. Зиновьев А. Идеологическая глобализация // Независимая газета. 2002. 26 февр.

5. Парадоксы медийной культуры: избр. статьи / Н. Б. Кириллова. - Екатеринбург: Изд-во Урал. ун-та. 2017452 c.

6. Кутырев В.А. Глобализация культуры: тенденции и противоречия - Н. Новгород, 2006.

7. Баранов М. Цифровое предприятие: пришло время перемен. PC Week, 2016, № 10. [Электронный ресурс] - Режим доступа: https://www.weekit.ru/idea/article/detail.php?ID=185915, свободный. - (дата обращения: 18.07.2019).

8. Стендинг Г. «Прекариат: новый опасный класс». - М.: Ад Маргинем Пресс, 2014. 328 с.

9. Аверкин А.Н., Гаазе-Рапопорт М.Г., Поспелов Д.А. Толковый словарь по искусственному интеллекту. - М.: Радио и связь, 1992. 256 с.

Ponomareva Irina Sergeevna, Candidate of economic Sciences, associate Professor of State, municipal Finance and financial engineering, Southern Federal University (43, 23-ya Liniya, Rostov-on-Don, 344019, Russian Federation). E-mail: isponomareva@sfedu.ru

Ponomarev Alexander Sergeevich, postgraduate student, Department of information technology security, Southern Federal University (Chekhov str., 2, building "I", Taganrog, 347922, Russian Federation).

E-mail: alponomarev@sfedu.ru.

\title{
ARTIFICIAL INTELLIGENCE AS A TOOL FOR THE DEVELOPMENT OF FINANCIAL GLOBALIZATION
}

\section{Abstract}

The use of artificial intelligence in the financial sector led to lower costs, an increase in the quality and speed of various types of banking operations, increased the accuracy of processes, which in turn made it possible to minimize the influence of the human factor and automate many processes. These technologies are one of the competitive advantages of financial institutions and the state as a whole in the global financial market, thereby giving another impetus to the development of financial globalization.

Keywords: financial globalization, digital economy, banks, financial institutions, information, information technologies, artificial intelligence, financial markets, credit and financial institutes.

\section{References}

1. Dorohov E. Ekonomicheskoe opredelenie globalizacii. [Elektronnyj resurs] - Rezhim dostupa: http://www.globalization.report.ru, svobodnyj. - (data obrashcheniya: 18.07.2019).

2. Ponomareva I.S. Vliyanie global'nogo finansovogo krizisa na razvitie finansovo-kreditnogo sektora // Terra Economicus. 2009. T. 7. № 4-2. P. 310 - 313.

3. Bogaturov A.D. Sindrom pogloshcheniya v mezhdunarodnoj politike // Pro et Contra. Osen' 1999. T. 4. №4. P. 32.

4. Zinov'ev A. Ideologicheskaya globalizaciya // Nezavisimaya gazeta. 2002. 26 fevr.

5. Paradoksy medijnoj kul'tury: izbr. stat'i / N. B. Kirillova. - Ekaterinburg: Izd-vo Ural. un-ta. 2017 - 452 s.

6. Kutyrev V.A. Globalizaciya kul'tury: tendencii i protivorechiya - N. Novgorod, 2006.

7. Baranov M. Cifrovoe predpriyatie: prishlo vremya peremen. PC Week, 2016, № 10. [Elektronnyj resurs] - Rezhim dostupa: https://www.weekit.ru/idea/article/detail.php?ID=185915, svobodnyj. - (data obrashcheniya: 18.07.2019).

8. Stending G. «Prekariat: novyj opasnyj klass». - M.: Ad Marginem Press, 2014. 328 s.

9. Averkin A.N., Gaaze-Rapoport M.G., Pospelov D.A. Tolkovyj slovar' po iskusstvennomu intellektu. - M.: Radio i svyaz', 1992. $256 \mathrm{~s}$.

удк 332.6

DOI: $10.22394 / 2079-1690-2019-1-3-164-168$

\section{СОВЕРШЕНСТВОВАНИЕ МЕТОДОЛОГИИ КАДАСТРОВОЙ ОЦЕНКИ ОБЪЕКТОВ НЕДВИЖИМОСТИ}

\begin{abstract}
Проскурина
Зинаида

Борисовна

кандидат экономических наук, доцент кафедры экономики и управления

недвижимостью, Российский государственный университет правосудия (117418,

Россия, г. Москва, ул. Новочеремушкинская, 69). E-mail: 7365313@ mail.ru
\end{abstract}

\section{Аннотация}

В статье рассмотрены основные проблемы определения кадастровой стоимости объектов недвижимости в России, а также проведен мониторинг поданных заявлений в судебные и внесудебные органы. Основываясь на полученных результатах, предложены дальнейшие перспективы развития кадастровой оценки недвижимости.

Ключевые слова: кадастровая стоимость, государственный кадастр недвижимости, стандарты, методы оценки, методологическая ошибка, инновационность, вложение инвестищий, налогоплательщики, кадастровая деятельность.

В условиях экономического кризиса, нестабильной финансовой ситуации, обесценения денег в Российской Федерации, одной из самых актуальных проблем у населения стало сбережение денежных накоплений, вложение их в надежные, стабильные и ликвидные инструменты.

Существующие особенности использования регионального потенциала и механизмы управления им предопределили глубокую дифференциацию инвестиционно-экономического положения 
регионов страны. Выравнивание социально-экономического положения является актуальной задачей и требует значительных вложений капитала. Как показывает изучение, в последнее время уровень конкуренции между регионами за привлечение инвестиций имеет устойчивую тенденцию к росту, что определяет прерогативу руководства регионов по выбору эффективных направлений развития, предусматривающих новые векторы взаимоотношений бизнеса, власти и рынка [1].

В современных условиях развитие любой экономической системы не возможно без использования эффективных инновационных технологий, базирующихся на учете и использовании совокупности факторов производства, отражающих требования мирового сообщества, что обеспечивает экономический рост [2].

При этом инновации необходимо рассматривать как деятельность, направленную на создание нового продукта: открытий, изобретений, патентов, конечным результатом реализации являются новые виды товаров, техники, технологии, методы и способы организации производства, труда и управления [3].

Таким образом, на современном этапе развития инновационность распространяется на все сферы экономической деятельности, охватывая все многообразие имеющихся на рынке товаров и услуг и основываясь на внедрении нововведений в жизнь людей на основе доходности [4].

Вместе с тем необходимо усилить контроль со стороны государственных органов за своевременностью и полноты выплаты заработной платы всем категориям трудящихся. Одним из важнейших направлений экономии живого труда на предприятиях является своевременная выплата заработной платы, увеличение ее доли в общем объёме реализованной продукции, повышение заработной платы работников, обеспечивающей высокий уровень жизни [5].

Одним из таких инструментов, который может приносить постоянный доход и сохранять капитал, являются вложения в недвижимость. Недвижимости, как любому объекту собственности, присуща такая количественная и качественная характеристика, как инвестиционная привлекательность, то есть коммерческий интерес у инвестора, состоящий в способности недвижимости приносить доход.

Рынок недвижимости, рассматриваемый как один из надежных и доходных способов вложения инвестиций, обеспечивающий сохранение и приумножение стоимости и величины капитала, включает в себя и присущие долгосрочным инвестициям факторы риска. Одним из таких факторов риска для собственников и арендаторов коммерческой недвижимости является сфера налогообложения.

Целесообразно отказываться от стимулирования сберегающей функции у населения, поскольку низкая потребительская активность затормаживает экономический рост, чем больше денег будет уходить в оборот, тем выше налоговые отчисления и, следовательно, рост статьи доходов в бюджете страны [6].

В настоящее время существуют проблемы определения кадастровой стоимости объектов недвижимости в России, они особенно актуальны для налогоплательщиков - владельцев недвижимости.

На данный период времени десятки тысяч налогоплательщиков в судах и во внесудебной форме оспаривают кадастровую стоимость своих земельных участков, которая в большинстве случаев оказывается в несколько раз выше их рыночной стоимости. Вследствие введения с 2015 г. налога на коммерческую недвижимость по кадастровой стоимости количество споров возрастет до сотен тысяч. Данные проблемы заметно увеличивают в стране социальную напряженность. Из-за занижения или завышения кадастровой стоимости объекта недвижимости граждане вынуждены обращаться в судебные органы, чтобы исправить ситуацию. Результаты определения кадастровой стоимости могут оспорить физические лица в суде или комиссии, если они затрагивают их права или обязанности.

Все проблемы определения кадастровой стоимости сводятся к одной главное проблеме - это недостоверность результатов определения кадастровой стоимости. На протяжении почти десяти лет в России рассматриваются десятки тысяч судебных и внесудебных дел об оспаривании кадастровой стоимости недвижимости. Обострение происходит из-за накопления проблем, связанных с кадастровой оценкой недвижимости, таких как: необоснованные отказы в комиссиях по заявлениям граждан; неверное составление отчетов оценщиками; методологическая ошибка.

Анализ показал, что за период с 01.01.2016 г. по 31.12.2017 г. в комиссии по рассмотрению споров о результатах определения кадастровой стоимости поступило 60288 заявлений за 2016 год и 73740 заявлений за 2017 год о пересмотре результатов определения кадастровой стоимости в отношении 275531 объектов недвижимости.

Результаты определения кадастровой стоимости могут быть оспорены: физическими лицами в случае, если результаты определения кадастровой стоимости затрагивают права и обязанности этих лиц; юридическими лицами в случае, если результаты определения кадастровой стоимости 
затрагивают права и обязанности этих лиц; органами государственной власти, органами местного самоуправления.

При оспаривании кадастровой стоимости в комиссии заинтересованному лицу необходимо обратиться в комиссию с соответствующим заявлением и требуемыми для пересмотра кадастровой стоимости документами.

Статистика заявлений включает в себя:

1) заявления по недостоверности сведений об объекте недвижимости, которые были использованы при определении кадастровой стоимости: 4051 заявление за 2016 год; 3248 заявления за 2017 год;

2) заявления по основанию установления в отношении объекта недвижимости его рыночной стоимости на дату, по состоянию на которую была установлена его кадастровая стоимость: 56174 заявления за 2016 год; 70461 заявление за 2017 год;

3) без указания основания: 62 заявления за 2016 год; 31 заявление за 2017 год;

4) с указанием двух оснований: 1 заявление за 2016 год; 2017 год - не зафиксировано ${ }^{1}$.

В ходе анализа выявлены необоснованные отказы комиссий по оспариванию кадастровой стоимости объекта недвижимости, что составляет немалую часть от всех заявлений (рис. 1).

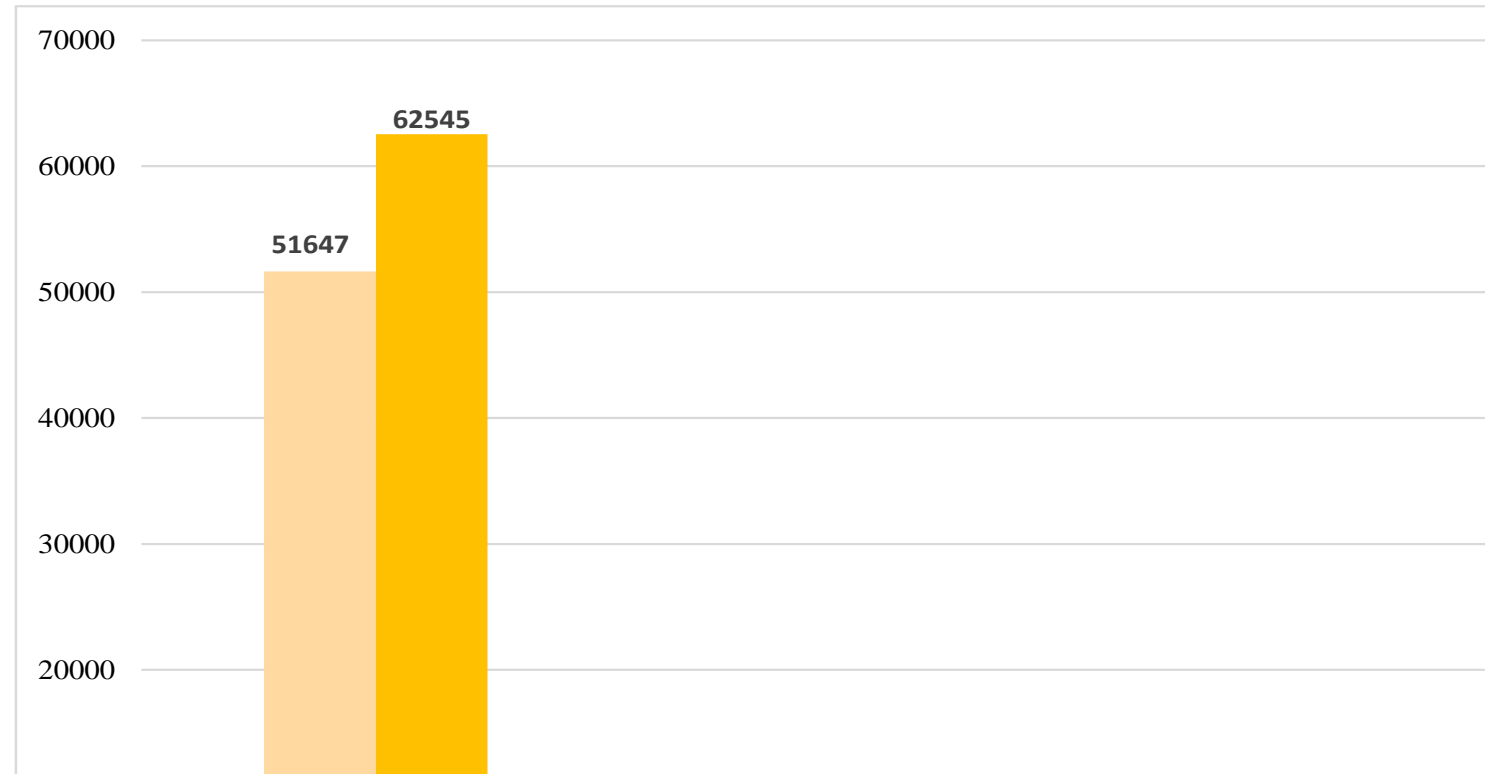

Рис. 1. Результаты приема заявлений об оспаривании кадастровой стоимости объектов недвижимости, которые были поданы в комиссии в 2016 - 2017 г2.

За следующий анализируемый период по состоянию на 31.12.2018 рассмотрено 10112 исков (18 983 объекта недвижимости): требования истцов удовлетворены в отношении 9283 исков (17 738 объектов недвижимости), не удовлетворены - в отношении 829 исков (1 245 объектов недвижимости).

На конец рассматриваемого периода на рассмотрении находится 6002 иска (10 845 объектов недвижимости).

В результате вынесенных в судебном порядке решений по искам, поступившим в суды в период с 01.01.2018 по 31.12.2018, наблюдается падение суммарной величины кадастровой стоимости в отношении объектов недвижимости, по которым были приняты решения, по состоянию на 31.12.2018 приблизительно на 718,2 млрд руб. (40,6 \%):

- суммарная величина кадастровой стоимости до оспаривания составляла около 1767,1 млрд руб.;

- после оспаривания - около 1048,9 млрд. руб.;

- суммарное снижение кадастровой стоимости в расчете на 1 объект - 40,5 млн. руб.

За указанный период по состоянию на 30.04.2019 рассмотрено 1884 иска (3088 объектов недвижимости): требования истцов удовлетворены в отношении 1779 исков (2980 объектов недвижимости), не удовлетворены - в отношении 105 исков (108 объектов недвижимости).

На конец рассматриваемого периода на рассмотрении находится 4248 исков (7 538 объектов недвижимости).

\footnotetext{
1 Официальный сайт Росреестра [Электронный источник] https://rosreestr.ru/site/
} 
В результате вынесенных в судебном порядке решений по искам, поступившим в суды в период с 01.04.2019 по 30.04.2019, наблюдается падение суммарной величины кадастровой стоимости в отношении объектов недвижимости, по которым были приняты решения, по состоянию на 30.04.2019 приблизительно на 41,5 млрд. руб. (56,5 \%):

- суммарная величина кадастровой стоимости до оспаривания составляла около 73,5 млрд руб.;

- после оспаривания - около 32,0 млрд. руб.;

- суммарное снижение кадастровой стоимости в расчете на 1 объект - 13,9 млн. руб. ${ }^{1}$

Комиссиями были зафиксированы следующие существенные недостатки в составлении отчетности: неверное оформление отчетности; не применение обязательных методы оценки; не обоснование отказа в использовании определенного метода; некорректная подборка объектааналога; неполное указание сведений об объекте оценки; неуместное применение метода массовой оценки.

Данные недостатки характеризуют и низкую квалификацию оценщиков, и отсутствие достоверной информации об объекте оценки и сделках с объектами-аналогами, и «давление» на оценщиков со стороны заказчиков, заинтересованных преимущественно в завышении кадастровой стоимости в своих регионах, и другие причины.

Основным риском обращения в комиссию по оспариванию кадастровой стоимости является некачественное выполнение отчета по результатам проведения оценки кадастровой стоимости. Также есть и верно составленные отчеты, но иск по-прежнему был оставлен без удовлетворения комиссией, поэтому необходимо обращаться в суд. Ранее такие иски рассматривал арбитражный суд, но сейчас они подлежат рассмотрению судами общей юрисдикции.

Основными причинами некачественного либо некорректного составления отчета по результатам проведения кадастровой оценки, являются в первую очередь низкая квалификация оценщика и наличие неполной информации об объекте аналоге и непосредственно об объекте оценки [7; 8]. По факту, оценщики руководствуются официальным источником об объектах недвижимости это Государственный кадастр недвижимости, который представляет из себя систематизированный свод сведений об учтенном недвижимом имуществе, сведения о прохождении границы между субъектами Российской Федерации, границах муниципальных образований и иных предусмотренных законом сведениями.

В настоящее время государственный кадастр недвижимости не отражает необходимую полноту сведений об объектах недвижимости и также о земельных участках. Государственный кадастр недвижимости не содержит экономических характеристик об объектах недвижимости, что является основополагающим для качественного проведения кадастровой оценки, также отсутствуют экологические сведения, что образует проблемы как в экономической деятельности субъектов, так и в судопроизводстве, и при проведении судебных экспертиз.

Наиболее острая проблема - методологическая ошибка при проведении кадастровой оценки, которая состоит в том, что кадастровая стоимость объекта недвижимости, которая была определена по итогам проведения массовой оценки, в дальнейшем оспаривается посредством данных рыночной стоимости объектов недвижимости, которые были рассчитаны по методу индивидуальной оценки. При применении двух разных методологий в итоге оценщик получает разные результаты.

Исходя из уровня существующих проблем в сфере кадастровой деятельности, можно представить дальнейшие перспективы развития кадастровой оценки недвижимости в России, а именно: выработка стратегических целей; квалификация оценщиков; разработка необходимых стандартов; изменения в отчетах о проведении кадастровой оценки.

Создание данных инструментов позволит государственным органам отслеживать сделки, осуществлять надзор за оценочной деятельностью в целом, проводить эффективный анализ цен на рынке недвижимости. С помощью создания электронного реестра можно решить проблему недостатка информации об объектах оценки, что позволит повысить качество кадастровой оценки.

\section{Литература}

1. Рябова Т.Ф., Маслюкова Е.А., Юткина О.В. Внутренние резервы роста экономики страны // Экономика и предпринимательство. 2018. № 8 (97). С. 1310 - 1313.

2. Маслюкова E.A. Воздействие макроэкономического развития на инновационное преобразование организаций пищевой промышленности, адаптированных к требованиям мирового рынка // Международные научные исследования. 2017. №2 (31). С. 246 - 250.

3. Минаева E.B., Юткина О.В. Направления эффективного управления предприятий малого и среднего бизнеса // Управленческие науки в современном мире. 2015. Т. 1. № 1. С. 31 - 34.

\footnotetext{
1 Официальный сайт Росреестра [Электронный источник] https://rosreestr.ru/site/
} 
4. Минаева E.В. Ключевое значение инновационного потенциала для развития организаций в условиях импортной зависимости страны // Экономика и предпринимательство. 2015. № 11 (ч.1). С. 605 - 608.

5. Проскурина 3.Б., Маслюкова Е.А., Юткина О.В. Диагностика заработной платы в агропромышленном комплексе по Российской Федерации // Экономика и предпринимательство. 2014. № 1-3 (42). С. 106 - 109.

6. Александрова М.В. Некоторые аспекты взаимодействия денежно-кредитного регулирования и бюджетно-налоговой политики государства в условиях кризис // Экономика и предпринимательство. 2015. № 11 (ч. 1). С. 108 - 112.

7. Крюков С.В., Лапшина А.С. Реформирование системы налогообложения и развитие кадастровой оценки недвижимости: проблемы и пути решения // Евразийский Научный Журнал. 2015. №12 (декабрь 2015). С. $212-216$.

8. Лапшина А.С. Сравнительный анализ подходов к определению размера налога на недвижимость на базе кадастровой и рыночной стоимостей объектов недвижимости// Journal of Economic Regulation. 2015. T. 6. № 3. С. 128 - 138.

Proskurina Zinaida Borisovna, Candidate of Economic Sciences, Associate Professor of the Department of Economics and Real Estate Management, Russian State University of Justice (69, Novocheremushkinskaya St., Moscow, 117418, Russian Federation). E-mail: 7365313@ mail.ru

\section{ENHANCEMENT OF METHODOLOGY OF CADASTRAL ASSESSMENT OF REAL ESTATE OBJECTS}

\section{Abstract}

The article considers the main problems of determining the cadastral value of real estate in Russia, as well as monitoring of applications submitted to judicial and extrajudicial bodies. Based on the results obtained, further prospects for the development of cadastral valuation of real estate are proposed.

Keywords: cadastral cost, State Immovable Property Cadastre, standards, assessment methods, methodological mistake, innovation, investment of investments, taxpayers, cadastral activity.

\section{References}

1. Ryabova T.F., Maslyukova E.A., YUtkina O.V. Vnutrennie rezervy rosta ekonomiki strany // Ekonomika i predprinimatel'stvo. 2018. № 8 (97). P. 1310 - 1313.

2. Maslyukova E.A. Vozdejstvie makroekonomicheskogo razvitiya na innovacionnoe preobrazovanie organizacij pishchevoj promyshlennosti, adaptirovannyh k trebovaniyam mirovogo rynka // Mezhdunarodnye nauchnye issledovaniya. 2017. №2 (31). P. 246 - 250.

3. Minaeva E.V., YUtkina O.V. Napravleniya effektivnogo upravleniya predpriyatij malogo i srednego biznesa // Upravlencheskie nauki v sovremennom mire. 2015. T. 1. № 1. P. 31 - 34.

4. Minaeva E.V. Klyuchevoe znachenie innovacionnogo potenciala dlya razvitiya organizacij v usloviyah importnoj zavisimosti strany // Ekonomika i predprinimatel'stvo. 2015. № 11 (ch.1). P. 605 - 608.

5. Proskurina Z.B., Maslyukova E.A., YUtkina O.V. Diagnostika zarabotnoj platy v agropromyshlennom komplekse po Rossijskoj Federacii // Ekonomika i predprinimatel'stvo. 2014. № 1-3 (42). P. 106 - 109.

6. Aleksandrova M.V. Nekotorye aspekty vzaimodejstviya denezhno-kreditnogo regulirovaniya i byudzhetnonalogovoj politiki gosudarstva v usloviyah krizis // Ekonomika i predprinimatel'stvo. 2015. № 11 (ch. 1). S. $108-112$.

7. Kryukov S.V., Lapshina A.S. Reformirovanie sistemy nalogooblozheniya i razvitie kadastrovoj ocenki nedvizhimosti: problemy i puti resheniya // Evrazijskij Nauchnyj ZHurnal. 2015. №12 (dekabr' 2015). S. $212-216$.

8. Lapshina A.S. Sravnitel'nyj analiz podhodov k opredeleniyu razmera naloga na nedvizhimost' na baze kadastrovoj i rynochnoj stoimostej ob"ektov nedvizhimosti// Journal of Economic Regulation. 2015. T. 6 . № 3. S. $128-138$. 